\title{
Variant of the Technique for Laryngeal Microsurgery in Cases of Difficult Laryngoscopy
}

\author{
Antonio Roberto Ferreira Setton ${ }^{1}$ Jeferson Sampaio D'avila ${ }^{1}$ Ricardo Queiróz Gurgel ${ }^{2}$ \\ Domingos Hiroshi Tsuji ${ }^{3}$ Daniel Vasconcelos D'avila ${ }^{3}$ Carlos Rodolfo Tavares de Góis ${ }^{1}$ \\ Ana Taise de Oliveira Meurer ${ }^{4}$ Helaina Peixoto Gurgel ${ }^{4}$
}

1 Department of Otorhinolaryngology, Faculty of Medicine,

Address for correspondence Ana Taise de Oliveira Meurer, MD,

Universidade Federal de Sergipe, Aracaju, SE, Brazil

2 Department of Pediatrics, Universidade Federal de Sergipe, Rua José Sotero, 325 - apto 102 - Bairro 13 de julho. Aracaju, SE, Aracaju, SE, Brazil

${ }^{3}$ Department of Otorhinolaryngology, Faculty of Medicine,

Universidade de São Paulo, São Paulo, SP, Brazil

${ }^{4}$ Department of Medicine, Faculty of Medicine, Universidade Federal

de Sergipe, Aracaju, SE, Brazil

Int Arch Otorhinolaryngol 2019;23:18-24.

\begin{abstract}
Keywords

- surgery

- endoscopy

- larynx

- technical variant

Introduction Low exposure of the larynx can make laryngeal microsurgery difficult or even impossible. The application of rigid and contact endoscopy enabled oblique and retrograde angled visualization, allowing transoperative staging with greater reach of the anatomical areas. However, there is difficulty or even impossibility of performing the surgical act, due to the incompatibility of the angled path with the straight surgical tools. Objective To demonstrate the efficiency of the variant of the technique for laryngeal microsurgery in cases of difficult laryngoscopy and to analyze the new surgical instruments specific to the endoscopic procedure.

Methods This is a cross-sectional retrospective study, based on the analysis of 30 medical records of patients treated surgically at a philanthropic hospital in the state of Sergipe, Brazil, between the years of 2014 and 2015.

Results The technical variant used 30- and 70-degree endoscopes that provided complete oblique view of the endolarynx. The association of angled instruments (forceps, suction pumps, retractors and scissors) enabled the execution of the surgical procedures. Conclusion The association of rigid endoscopy with angled instruments promoted full visualization of the surgical lesion and operative resolution.
\end{abstract}

\section{Introduction}

Laryngeal microsurgery is the method of endoscopic treatment of laryngeal lesions. ${ }^{1,2}$ When laryngoscopy is difficult, there may be no visualization of part or even of all the vocal cords with the use of conventional laryngoscopy, in such a way as to make laryngeal microsurgery difficult or even impossible to perform. ${ }^{3}$

received

November 17, 2017

accepted

April 21, 2018

published online

August 9, 2018

10.1055/s-0038-1660825. ISSN $1809-9777$.
The physical examination, in most cases, is enough to alert, even in the preoperative stage, about potential problems in access to the airway. Some findings, such as micrognathia and mandibular anteriorization, as well as measures of cervical circumference and modified Mallampati index, are known for predicting the risk of difficult airway exposure. ${ }^{4,5}$

Laryngeal microsurgery promotes magnification of the image and the possibility of visualization of the

Copyright @ 2019 by Thieme Revinter

Publicações Ltda, Rio de Janeiro, Brazil

License terms

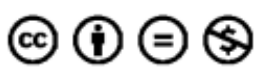


endolaryngeal anatomical structures, but with the view being exclusively frontal, that is, in a straight line. ${ }^{6}$ With the application of rigid and contact endoscopy developed by Andrea and Dias, there was the possibility of angular oblique and retrograde visualization, allowing better visualization and transoperative staging with greater reach of the anatomical areas. ${ }^{7}$

D'Avila's study demonstrated that the anatomical area of lesser visualization during difficult exposure of the larynx is the anterior area of the larynx (area I), which corresponds to the anterior third of the vocal folds and anterior commissure region (-Fig. 1). ${ }^{8}$ To obtain visualization of this area, and in certain cases of area II, the application of rigid endoscopes of 30 and 70 degrees becomes necessary.

Once this more efficient viewing option was adopted, the next challenge to perform the surgical procedure was instrumentation limitation. Generally, despite the surgical lesions being visible with the use of the angled endoscope, there is difficulty or even impossibility of performing the surgical act due to the incompatibility of the angled path with the straight surgical tools.

A retrospective study was performed to analyze the medical records of 30 patients, identifying 6 anatomical parameters of surgical patients submitted to laryngeal microsurgery, namely: cervical circumference, oral opening, thyromental distance, modified Mallampati classification, laryngeal anteriorization and micrognathia. Out of the 30 patients, 6 had difficulty in laryngeal exposure and were thus selected to be evaluated in relation to these anatomical parameters.

The objective of this work is to demonstrate the efficiency of the variant of the technique for laryngeal microsurgery

\section{AREA I}

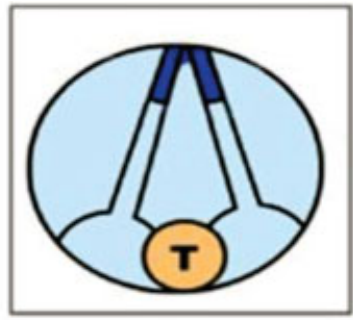

AREA II

AREA III
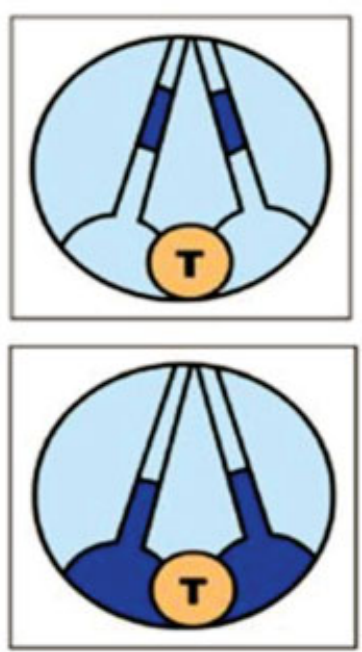

Fig. 1 D’Avila's areas.

with difficult laryngoscopy and to analyze the new surgical instruments specific to the endoscopic procedure.

\section{Methods}

\section{Study Design}

This is a retrospective cross-sectional study of the medical records of 30 patients, over 12 years old, with laryngeal lesions between the years of 2014 and 2015.

\section{Place of Study}

The study was performed in the city of Aracaju, capital of the state of Sergipe, located in the Northeast region of Brazil. The data were collected at the Otorhinolaryngology Service of a philanthropic hospital in the state of Sergipe, which is the same place where the patients were treated surgically.

\section{Study Population}

The study group consisted of 32 patients with various larynx lesions and surgically treated in the years 2014 and 2015. Of these, two did not sign the consent form and were then excluded. In 24 subjects, the classic surgical technique was employed, and in 6 of them, a technical variant was successfully adopted, which was used as a last resort for adequate laryngeal exposure and worthy of subsequent analysis. Patients younger than 12 years old were not included in the study due to the anatomical variability of this age group.

\section{Data Collection}

We initially cataloged all the clinical and surgical records of the patients that contained the data of the anthropometric measurements and the surgical technique used (classic or variant) and whose individuals were older than 12 years. The material for collection of the anthropometric measures was composed of tape measure, metallic ruler and caliper (-Fig. 2). The measurements collected were of oral opening, cervical circumference, thyromental distance, as well as the presence or not of micrognathia, laryngeal anteriorization and modified Mallampati index. The gender, age and weight of individuals were also collected. All the mentioned data were found in the patient evaluation sheets attached to the clinical and surgical charts.

The measurement of the cervical circumference was obtained with inextensible tape scaled in centimeters and at the level of the thyroid cartilage, in a neutral position (-Fig. 3).

The oral opening measurement was obtained with the mouth opened at maximum, from the tip of the upper to the lower incisors, by a caliper scaled in millimeters (-Fig. 4).

The thyromental distance was measured with a metal ruler scaled in centimeters and with the patient in a position of slight extension of the neck, from the mental prominence to the prominence of the thyroid cartilage (-Fig. 5).

The evaluation of laryngeal anteriorization was obtained through the patients' profile photograph, in a neutral position. 


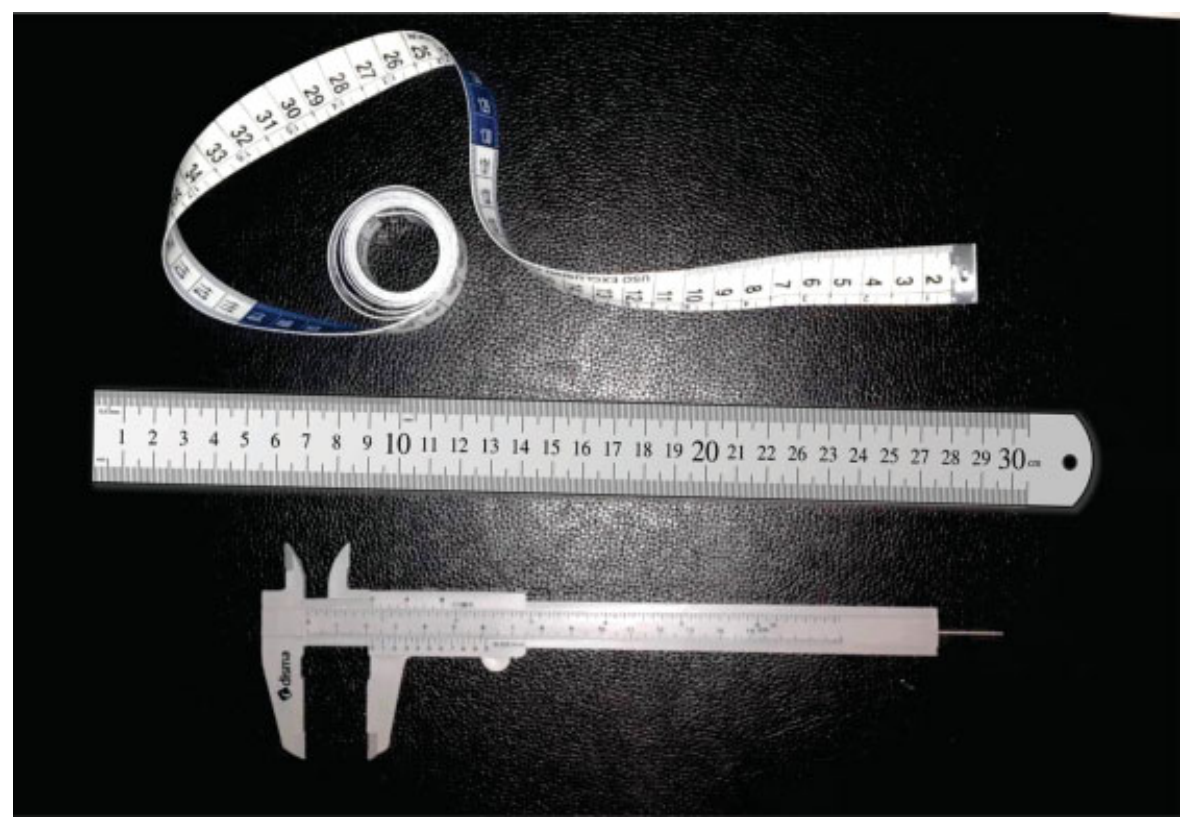

Fig. 2 Material for collection of anthropometric measurements.

The presence of micrognathia was determined by means of profile photography, in neutral position.

The registration of the modified Mallampati index was obtained through the direct inspection of the patients' pharynges by the researcher himself, asking them to open the mouth as proposed in the literature for this type of examination, and following the following parameters: grade $1=$ visible tonsils, pillars and soft palate; grade 2 = only uvula, pillars and upper pole of tonsils visible; grade 3 = partially visible soft palate; grade $4=$ only hard palate visible.

\section{Implementation of the Technical Variant}

After evidencing the lack of possibility of visual access to the D'Avila's Areas, especially Area I, which corresponds to the anterior third of the vocal folds and the anterior commissure of the larynx, it was introduced the first and important

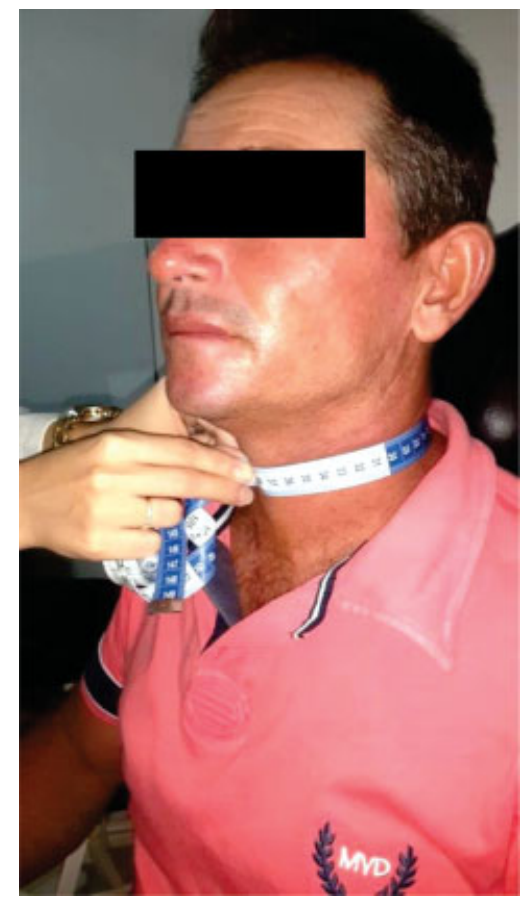

Fig. 3 Measurement of cervical circumference.

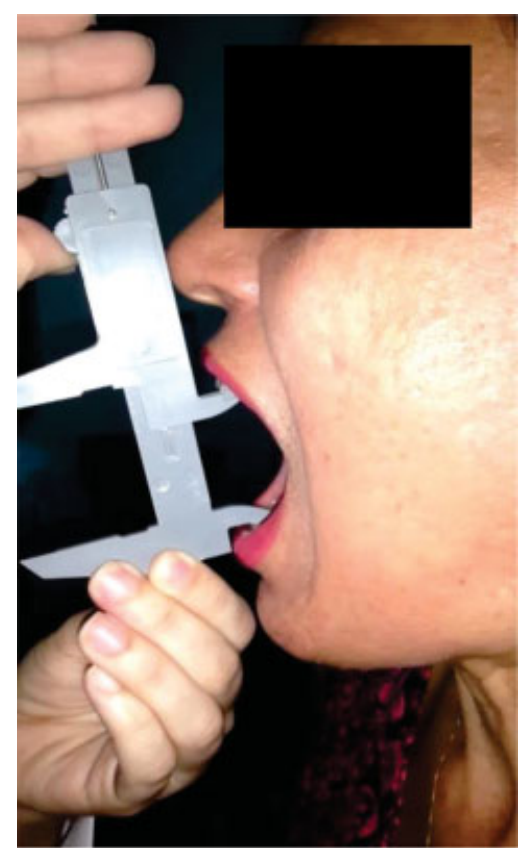

Fig. 4 Measurement of oral opening. 


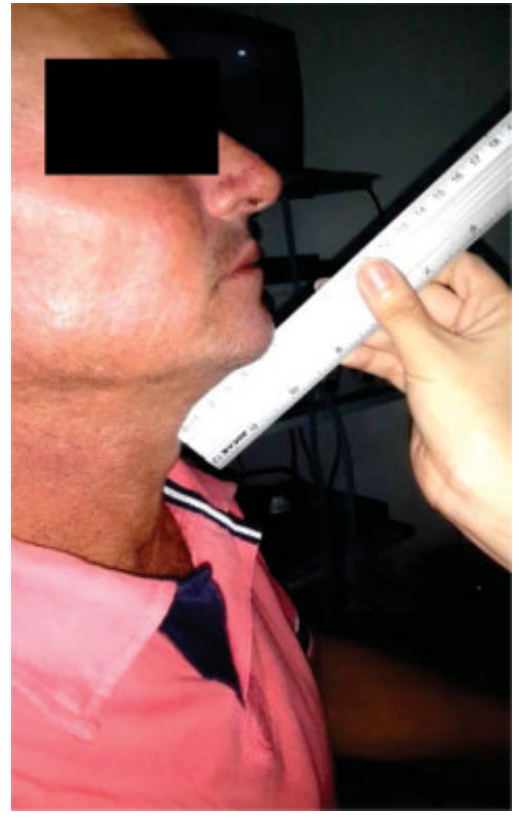

Fig. 5 Measurement of thyromental distance.

parameter for the execution of the variant surgery, which was applied by the rigid endoscopies of Andrea and Dias. ${ }^{9}$

Using the 30- and 70-degree endoscopes, anatomical structures were identified in angular visual form, a possibility that does not exist with the straight vision of the optical microscopy.

The second parameter of great relevance for the execution of the surgery would be the need to have surgical instruments also angled, which could reach the lesions to be resected. The lack of access to angled instruments to perform these procedures, guided the development of this type of material (-Fig. 6).

That is, angled forceps, suction pumps, retractors and scissors were designed and developed and have been successfully applied in these procedures in surgical execution.

\section{Variables Analyzed}

Two types of variables were analyzed: categorical variables (oral opening, cervical circumference and thyromental dis-

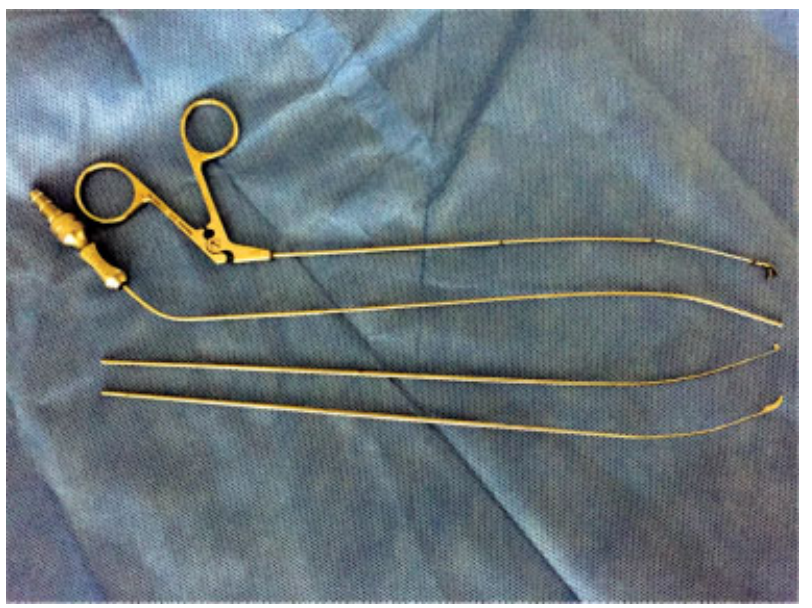

Fig. 6 Material developed for the technical variant. tance) and non-categorical variables (micrognathia, laryngeal anteriorization and modified Mallampati index). In addition to those mentioned and chosen as the object of our study because they were the most relevant in clinical practice, it was opted to analyze, in a complementary way, the weight and the age of all the participants of the sample. The surgical technique used was recorded, whether conventional (using microscopy and straight instruments) or variant (with angled instruments and rigid endoscopes with varied angulations), the latter used as a last resort for satisfactory laryngeal exposure during surgery. Thus, the relation between the variables collected and a difficult intraoperative laryngeal exposure was analyzed.

\section{Statistical Analyzes}

The data were statistically analyzed by means of simple and percentage frequencies when categorical variable or mean and standard deviation when continuous variable. Fisher's Exact test was used to evaluate the existing associations, and these were graphically represented by multiple correspondence analysis. The mean differences were tested by the Mann-Whitney test. Relative risks were adjusted to their respective confidence intervals through univariate Cox Regression and the software used was the $\mathrm{R}$ Core Team 2017 , with a significance level of $5 \%$.

\section{Ethical Aspects}

The project was submitted to the Ethics Committee in Research involving human beings of the Federal University of Sergipe - CEP/UFS and approved under the CAAE 55215416.5.0000.5546. The participants signed the Term of Free and Informed Consent, and the complete confidentiality of the collected data was ensured.

\section{Results}

Thirty patients were analyzed, among which 15 were male and 15 female. Their ages ranged from 14 to 81 years. The majority of the individuals in our study were between 18 and 59 years old (76.6\% of the total), with a mean age of 48 years. The weight of the individuals varied between 42 and $91 \mathrm{~kg}$, with the majority of individuals being between 50 and $75 \mathrm{~kg}$.

All the variables collected as possible predictive factors of difficult laryngeal exposure were analyzed statistically and correlated to the surgical technique used ( $\mathbf{- T a b l e ~} \mathbf{1}$ ).

It was concluded that, of the 30 patients submitted to laryngeal microsurgery, there were 6 cases with difficult surgical exposure, which made it necessary to employ the technical variant. The impossibility of partial and/or total exposure of the larynx guided the development of a technical variant, which not only allowed visualization of the organ and its respective disease, but also allowed the execution of the proposed surgical procedure.

The focus of our research is the study of these six cases in which the technical variant, described below, was minutely used. Was used the standard of normality described in the literature for each anatomical parameter searched. 
22 Variant of the Technique for Laryngeal Microsurgery Setton et al.

Table 1 Comparative analysis of the presence of predictive factors of difficult laryngeal exposure between the samples submitted to the technical variant and to the classic technique

\begin{tabular}{|l|l|l|l|l|}
\hline & Technical variant $(\boldsymbol{n}=\mathbf{6})$ & Classical technique $(\boldsymbol{n}=\mathbf{2 4})$ & $\mathbf{p}$-value & RCR (95\%Cl) \\
\hline Laryngeal anteriorization (\%) & & & & \\
\hline Yes & $03(50 \%)$ & $0(0 \%)$ & 0.005 & $9(1.82-44.6)$ \\
\hline No & $03(50 \%)$ & $24(100 \%)$ & & \\
\hline Micrognathia (\%) & & & & \\
\hline Yes & $03(50 \%)$ & $0(0 \%)$ & 0.005 & $9(1.82-44.6)$ \\
\hline No & $03(50 \%)$ & $24(100 \%)$ & & \\
\hline Cervical circumference & & & & \\
\hline Mean (SD) & $39.42( \pm 3.92)$ & $37.19( \pm 2.79)$ & $0.102^{*}$ & \\
\hline$>40 \mathrm{~cm}(\%)$ & $03(50 \%)$ & $2(8.3 \%)$ & 0.041 & $5(1.01-24.8)$ \\
\hline$\leq 40 \mathrm{~cm}(\%)$ & $03(50 \%)$ & $22(91.7 \%)$ & & \\
\hline Oral opening & & & & \\
\hline Mean (SD) & $4.33( \pm 0.60)$ & $4.87( \pm 0.69)$ & $0.092^{*}$ & \\
\hline$<4.5 \mathrm{~cm}(\%)$ & $04(66.7 \%)$ & $7(29.2 \%)$ & 0.156 & $3.45(0.63-18.9)$ \\
\hline$\geq 4.5 \mathrm{~cm}(\%)$ & $02(33.3 \%)$ & & & \\
\hline Thyromental distance & & $6.26( \pm 1.24)$ & & \\
\hline Mean (SD) & $6.25( \pm 1.17)$ & $7(29.2 \%)$ & $0.975^{*}$ & \\
\hline$<6 \mathrm{~cm}(\%)$ & $02(33.3 \%)$ & $17(70.8 \%)$ & 1.000 & $1.17(0.21-6.37)$ \\
\hline$\geq 6 \mathrm{~cm}(\%)$ & $04(66.7 \%)$ & $5(20.8 \%)$ & & \\
\hline Mallampati index (\%) & & $19(79.2 \%)$ & 0.009 & $10(1.17-85.6)$ \\
\hline Classes III and IV & $5(83.3 \%)$ & & \\
\hline Classes I and II & $1(16.7 \%)$ & & \\
\hline
\end{tabular}

Abbreviations: $95 \% \mathrm{Cl}$, 95\% confidence interval; RCR, relative conditional risk; SD, standard deviation.

*Mann-Whitney test.

\section{Case 01}

A.V.A., 46 years old, male gender, $74 \mathrm{~kg}$.

Surgical disease: bilateral leukoplakia vocal fold

\section{Case 02}

M. H. B. S., 46 years old, female gender, $56 \mathrm{~kg}$.

Surgical disease: bilateral Reinke edema

\section{Case 03}

A.S.S.E., 57 years old, male gender, $95 \mathrm{~kg}$.

Surgical disease: Cyst right vocal fold

\section{Case 04}

M.J.J.S., 46 years old, female gender, $82 \mathrm{~kg}$.

Surgical Disease: vocal folds nodules

\section{Case 05}

J.A.S., 37 years old, male gender, $61 \mathrm{~kg}$

Surgical Disease: polyp right vocal fold

\section{Case 06}

J.D.M.A., 55 years old, male gender, $80 \mathrm{~kg}$.

Surgical disease: bilateral leukoplakia vocal fold
In - Table 2, we can see that three patients presented altered measurements of cervical circumference (greater than the reference value), four had a lower oral opening, and two were the patients who presented lower thyromental distance, laryngeal anteriorization and micrognathia. Four patients presented alteration of the classification of modified Mallampati, being 2 in class 3 and 2 in class 4 .

\section{Discussion}

The preoperative evaluation of the surgical patient, using classification parameters and measures, favors the identification of possible difficulties of surgical exposure. In the general population, the reported rate of difficult larynx exposure is $5.8 \%$, according to standardized ratings of Cormack and Lehanne. ${ }^{10}$ This situation must be reported to the patient. The same has the right to know about the possibility of surgical difficulty or even suspension of this act due to the lack of accessibility. In addition to respecting ethical principles regarding the patient, this attitude promotes legal protection of the medical team in case of failure.

The variables analyzed in this study are similar to those of other correlated studies, but the most relevant ones were 
Table 2 Presence of predictive factors of difficult laryngeal exposure in the sample submitted to the technical variant

\begin{tabular}{|c|c|c|c|c|c|c|c|c|c|c|}
\hline \multirow[t]{2}{*}{ Patient } & \multicolumn{2}{|c|}{$\begin{array}{l}\text { Cervical } \\
\text { circumference }\end{array}$} & \multicolumn{2}{|c|}{ Oral opening } & \multicolumn{2}{|c|}{$\begin{array}{l}\text { Thyromental } \\
\text { distance }\end{array}$} & \multicolumn{2}{|c|}{$\begin{array}{l}\text { Modified } \\
\text { Mallampati } \\
\text { classification }\end{array}$} & \multirow{2}{*}{$\begin{array}{l}\text { Laryngeal } \\
\text { anteriorization } \\
\text { YES or NO }\end{array}$} & \multirow{2}{*}{$\begin{array}{l}\text { Micrognathia } \\
\text { YES or NO }\end{array}$} \\
\hline & $\mathrm{RV}^{*}$ & REAL & RV & REAL & RV & REAL & RV & FOUND & & \\
\hline A.V.A & $<40 \mathrm{~cm}$ & $41 \mathrm{~cm}$ & $>4.5 \mathrm{~m}$ & $4.0 \mathrm{~cm}$ & $>6.0 \mathrm{~cm}$ & $7.0 \mathrm{~cm}$ & $\begin{array}{l}\text { CLASS } \\
1 \text { or } 2\end{array}$ & $\begin{array}{l}\text { CLASS } \\
3\end{array}$ & NO & YES \\
\hline M.H.B.S & $<40 \mathrm{~cm}$ & $33.5 \mathrm{~cm}$ & $>4.5 \mathrm{~m}$ & $5.5 \mathrm{~cm}$ & $6.0 \mathrm{~cm}$ & $6.5 \mathrm{~cm}$ & $\begin{array}{l}\text { CLASS } \\
1 \text { or } 2\end{array}$ & $\begin{array}{l}\text { CLASS } \\
4\end{array}$ & NO & NO \\
\hline A.S.S.E & $<40 \mathrm{~cm}$ & $44 \mathrm{~cm}$ & $>4.5 \mathrm{~m}$ & $4.0 \mathrm{~cm}$ & $>6.0 \mathrm{~cm}$ & $6.0 \mathrm{~cm}$ & $\begin{array}{l}\text { CLASS } \\
1 \text { or } 2\end{array}$ & $\begin{array}{l}\text { CLASS } \\
3\end{array}$ & NO & YES \\
\hline M.J.J.S & $<40 \mathrm{~cm}$ & $40 \mathrm{~cm}$ & $>4.5 \mathrm{~m}$ & $4.0 \mathrm{~cm}$ & $>6.0 \mathrm{~cm}$ & $5.0 \mathrm{~cm}$ & $\begin{array}{l}\text { CLASS } \\
1 \text { or } 2\end{array}$ & $\begin{array}{l}\text { CLASS } \\
3\end{array}$ & NO & NO \\
\hline J.A.S & $<40 \mathrm{~cm}$ & $36 \mathrm{~cm}$ & $>4.5 \mathrm{~m}$ & $4.5 \mathrm{~cm}$ & $>6.0 \mathrm{~cm}$ & $5.0 \mathrm{~cm}$ & $\begin{array}{l}\text { CLASS } \\
1 \text { or } 2\end{array}$ & $\begin{array}{l}\text { CLASS } \\
1\end{array}$ & YES & NO \\
\hline J.D.M.A & $<40 \mathrm{~cm}$ & $42 \mathrm{~cm}$ & $>4.5 \mathrm{~m}$ & $4.0 \mathrm{~cm}$ & $>6.0 \mathrm{~cm}$ & $8.0 \mathrm{~cm}$ & $\begin{array}{l}\text { CLASS } \\
1 \text { or } 2\end{array}$ & $\begin{array}{l}\text { CLASS } \\
4\end{array}$ & YES & YES \\
\hline
\end{tabular}

Abbreviation: RV, reference value in the literature.

selected for this study based on the 30-year experience of the referral service in laryngeal surgery, where the research was developed.

The surgical technique adopted was distributed as classic or conventional in 24 individuals (80\%) and variant of the technique in 6 individuals (20\%), successfully adopted in all cases that presented difficulty of surgical larynx exposure. Their results are demonstrated in another article.

The most common pathologies in our sample were vocal cysts and polyps, with 5 cases each (17\%), followed by Reinke edema, squamous cell carcinoma, vocal dysplasia and vocal nodules, with 4 cases each (13\%). There were also 2 cases of vocal granuloma (7\%) and 1 case of vallecula cyst and another case of laryngeal papillomatosis (3\% each). Studies on this subject are scarce in our country, but our findings are corroborated by Ballin et $\mathrm{al}^{11}$ who found a prevalence of polyps in their study (36.84\%), followed by intracordial cysts and laryngeal papillomatosis (15.79\% each), with cases of vocal nodules and Reinke edema, among others.

The researched sample composed of 30 individuals was enough to present statistical relevance. The sample size matches perfectly the number of individuals surgically treated in the 12-month period at the referral service in laryngeal surgery in the state where the study was developed. Some factors contribute to the reduced number of laryngeal surgeries performed annually, among them the small population of the state in which the research was performed, as well as the lack of knowledge of the population regarding the importance of vocal health.

It is noteworthy that the application of this technical variant could allow adequate surgical accessibility without causing iatrogenic lesions due to a forced exposure attempt. Despite the existence of suspension laryngoscopes with a variety of angulations and calibers, it is important to understand that the limits for their application must be respected. In this way, iatrogenic lesions, such as those affecting the palate, tongue, epiglottis, pharyngeal lateral wall and several dental structures, can be avoided with the use of this technical variant.

As an important limiting factor of this variant, we defined the use of only one hand to manipulate the instrument, since the surgeon's other hand must necessarily be holding the angled endoscopes. The possibility of attaching these endoscopes to allow the use of both hands was ruled out because these surgical procedures are essentially dynamic and require constant mobilization. Studies have shown that the addition of an adapter to the laryngoscope to support the rigid and angled endoscope seems to be the pathway for bimanual standard laryngeal surgery. ${ }^{12,13}$

As an important finding in this series of cases, we refer to the repetition of vocal fold leukoplakia (two cases). The variability of diseases associated with differentiated predictive factors guides the surgeon to routinely perform the preoperative analysis of the predictive factors of difficult laryngeal exposure regardless of the surgical indication.

In spite of these surgical limitations, in cases in which the technical variant was applied, removal of the surgical lesion was fully performed in the sample. The use of angular surgical instruments demonstrated efficacy and respect to the principles of the phonomicrosurgery.

\section{Conclusion}

The association of rigid endoscopy with angled instruments promoted full visualization of the surgical lesion and operative resolution.

\section{References}

1 Kawaiada M, Fukuda H, Kohno N. Multidirectional observations of the larynx using transurethral rigid endoscopes during direct laryngoscopy. J Laryngol Otol 2012;112(05):464-466 
2 Wambier H, Sonego TB, Batista FC, Kohler R. Lesões pré-malignas da laringe: revisão de literatura. Rev. Bras. Cir. Cabeça Pescoço. 2012;41(01):42-47

3 Alarcon JB, Mesa A. Manual clínico da via aérea respiratória. São Paulo: Artes Medi; 2004

4 Pinar E, Calli C, Oncel S, Selek B, Tatar B. Preoperative clinical prediction of difficult laryngeal exposure in suspension laryngoscopy. Eur Arch Otorhinolaryngol 2009;266(05):699-703

5 Hsiung MW, Pai L, Kang BH, Wang BL, Wong CS, Wang HW. Clinical predictors of difficult laryngeal exposure. Laryngoscope 2004; 114(02):358-363

6 Kleinsasser O. Microlaryngoscopy and Endolaryngeal Microsurgery. ${ }^{\text {rd }}$ Ed. Philadelphia: Hanley; 1991:593-594

7 Andréa M, Dias O, Santos A. Contact endoscopy during microlaryngeal surgery: a new technique for endoscopic examination of the larynx. Ann Otol Rhinol Laryngol 1995;104(05):333-339

8 D'avila JS, Sennes LU, Tsuji DH. Estudo comparativo da microvascularização das cordas vocais humanas acometidas por cisto e reação nodular contra-lateral, "in vivo", através das endoscopias rígidas e de contato da laringe. Rev Bras Otorrinolaringol 2003;69 (02):166-173

9 Andréa M, Dias O. Rigid and contact endoscopy in microlaryngeal surgery: technique and atlas of clinical cases. Philadephia: Lippincott-Raven; 1995:1-110

10 Cormack RS, Lehane J. Difficult tracheal intubation in obstetrics. Anaesthesia 1984;39(11):1105-1111

11 Ballin AC, Dacheux E, Filho DM, et al. Avaliação Sistematizada da Dificuldade de Exposição das Pregas Vocais na Microcirurgia da Laringe Difficulty Systematized Evaluation of Vocal Folds Exposure in Microsurgery of the Larynx. Arq Int Otorrinolaringol 2010; 14(03):294-301

12 Friedrich G, Kiesler K, Gugatschka M. Curved rigid laryngoscope: missing link between direct suspension laryngoscopy and indirect techniques? Eur Arch Otorhinolaryngol 2009;266(10):1583-1588

13 Xidong C, Xia Z, Chenjie X, Wenhong Y, Huichang Y, Jiaqi J. Management of difficult suspension laryngoscopy using a GlideScope ${ }^{\circledR}$ Video Laryngoscope. Acta Otolaryngol 2012;132(12): 1318-1323 